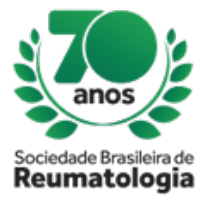

\title{
EXPERIENCE REPORT ABOUT A RHEUMATOLOGY HEALTH "MUTIRAO"
}

Guilherme Bitu dos Santos Ponte (Universidade de Fortaleza, Fortaleza, CE, Brasil), Ana Clara Feitosa Bezerra (Universidade de Fortaleza, Fortaleza, CE, Brasil), Ana Natália Vasconcelos Arcanjo (Universidade de Fortaleza, Fortaleza, CE, Brasil), Maria Paula Lopes Ponte Prado (Universidade de Fortaleza, Fortaleza,

CE, Brasil), Sâmia Arruda Freire Ribeiro (Universidade de Fortaleza, Fortaleza, CE, Brasil), Max Victor Carioca Freitas (Universidade de Fortaleza, Fortaleza, CE, Brasil)

\section{BACKGROUND}

Health "mutirões" are actions of collective mobilization in order to bring care, services and dignity to patients with less health assistance. Besides improving health access in more distant areas, they are also fundamental for the early insertion of the medical student in the practice of medicine, which allows an approximation with the social reality, far from the teaching laboratories. This insertion provides the enrichment of students' abilities concerning anamnesis and physical examination of different diseases, and also develops a sense of responsibility towards the other.

\section{MATERIALS AND METHODS}

The rheumatology health "mutirão" took place on November 10, 2018, in the Núcleo de Atenção Médica Integrada (NAMI), a secondary care unit, part of the Universidade de Fortaleza (UNIFOR). During the event, UNIFOR's medical students between the second and sixth year of the course assisted 80 patients from the municipalities of Mulungu, Aratuba, Aracati and São Gonçalo do Amarante, all located in the State of Ceará. This action was done under the supervision of five rheumatologists, who are also professors of the UNIFOR medical school. During this activity, ten offices were used for attendance. Three to four academics were placed in each room. It was sought to allocate students from more advanced semesters with those who were of the initials ones. Each rheumatologist was responsible for two offices.

\section{RESULTS}

The "mutirão" was an enriching experience for the students, since they were able to apply in practice the knowledge acquired during the graduation, discussing each case with a teacher and contributing to the health of 80 patients. They observed the difficulty of access and assistance in secondary care units and the great psychosocial repercussion that those diseases caused in this population. Also, the action benefited a total of 80 people and many of them were able to continue the monitoring of their diseases in NAMI.

\section{CONCLUSION}

This experience provided another way of learning for medical students, since there was an opportunity to put into practice the theory and the semiology of rheumatology, already acquired during the academic formation. In addition, the rich discussions of the cases during the effort were fundamental to improve their knowledge. Moreover, the patients were benefited by the attending, since in the municipalities contemplated is difficult for them to obtain the assistance with medical specialists. 